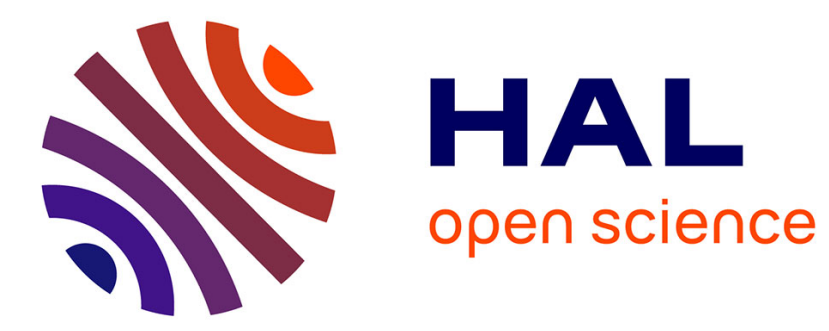

\title{
Convergent synthesis of digitally-encoded poly(alkoxyamine amide)s
}

Raj Kumar Roy, Chloé Laure, Diane Fischer-Krauser, Laurence Charles, Jean-François Lutz

\section{To cite this version:}

Raj Kumar Roy, Chloé Laure, Diane Fischer-Krauser, Laurence Charles, Jean-François Lutz. Convergent synthesis of digitally-encoded poly(alkoxyamine amide)s . Chemical Communications, 2015, 51 (86), pp.15677-15680. 10.1039/c5cc06646h . hal-01258279

\section{HAL Id: hal-01258279 \\ https://hal-amu.archives-ouvertes.fr/hal-01258279}

Submitted on 18 Jan 2016

HAL is a multi-disciplinary open access archive for the deposit and dissemination of scientific research documents, whether they are published or not. The documents may come from teaching and research institutions in France or abroad, or from public or private research centers.
L'archive ouverte pluridisciplinaire HAL, est destinée au dépôt et à la diffusion de documents scientifiques de niveau recherche, publiés ou non, émanant des établissements d'enseignement et de recherche français ou étrangers, des laboratoires publics ou privés. 


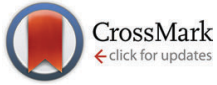

Cite this: Chem. Commun., 2015, 51, 15677

Received 7th August 2015,

Accepted 5th September 2015

DOI: $10.1039 / \mathrm{c5cc06646h}$

www.rsc.org/chemcomm

Binary-encoded poly(alkoxyamine amide)s were prepared by oligomer ligation. These polymers contain digital sequences based on two monomers defined as 0 and 1 bits. A library of oligomers containing all possible dyads $00,01,10$ and 11 was prepared and used to construct long coded sequences.

Polymers containing sequence-encoded digital information have recently been identified as a promising new class of synthetic macromolecules. ${ }^{1}$ Similarly to natural nucleic acids these polymers contain a string of information that can be decoded and eventually interpreted. ${ }^{2}$ The encoded monomer sequences can be prepared using iterative solid-phase methodologies and can be analyzed using sequencing tools that have been developed for genomics or proteomics. ${ }^{3}$ For instance, our group has recently described different types of non-natural information-containing macromolecules such as polyphosphates, ${ }^{4}$ poly(triazole amide) ${ }^{5}$ and poly(alkoxyamine amide)s. ${ }^{6}$ The latter polymers were found to be particularly appealing since their sequences can be easily written, read and erased. Indeed, monodisperse poly(alkoxyamine amide)s can be efficiently synthesized using a protecting-group-free approach involving two orthogonal coupling steps, namely amineanhydride coupling and radical-radical coupling. ${ }^{6}$ These polymers can also be accurately sequenced by tandem (MS/MS) mass spectrometry since they contain weak alkoxyamine links that enhance their MS/MS readability. ${ }^{7}$ In that regard, these polymers are probably easier to sequence by mass spectrometry than DNA or proteins. Moreover, poly(alkoxyamine amide)s are thermo-labile and their sequences can be erased by heating. ${ }^{6}$

Sequence-defined polymers are usually synthesized using a monomer-by-monomer iterative approach. ${ }^{8}$ Thus, numerous chemical steps are needed to construct these polymers. However,

\footnotetext{
${ }^{a}$ Precision Macromolecular Chemistry Group, Institut Charles Sadron,

23 rue du Loess, BP84047, 67034 Strasbourg Cedex 2, France.

E-mail: jflutz@unistra.fr; Fax: +33 3884140 99; Tel: +33 88414016

${ }^{b}$ Aix-Marseille Université - CNRS, UMR 7273, Institute of Radical Chemistry, 13397 Marseille Cedex 20, France

$\dagger$ Electronic supplementary information (ESI) available: Full experimental part and Fig. S1-S12. See DOI: 10.1039/c5cc06646h
}

the synthesis of monodisperse macromolecules can be greatly simplified by using convergent strategies. For instance, the groups of Hercules, Brooke and Hawker have shown that monodisperse polymers can be easily attained by iterative exponential growth. ${ }^{9}$ Kent and coworkers have also reported that the total synthesis of high-molecular weight proteins can be eased by convergent ligation strategies. ${ }^{10}$ In a recent publication, we have shown that information-containing macromolecules can be efficiently synthesized by stepwise ligation of dyad-encoded oligomers. ${ }^{5 c}$ Strictly speaking, this approach is only partly-convergent since it still involves oligomer-based iterative coupling steps. However, it permits to reduce by half the number of coupling steps as compared to the traditional approach. Here, this concept is applied to the class of poly(alkoxyamine amide)s.

Information-containing poly(alkoxyamine amide)s contain coded amide moieties linked together by 2,2,6,6-tetramethylpiperidine-1-oxyl (TEMPO)-based alkoxyamine spacers. They are usually synthesized by successive orthogonal coupling of bromo-anhydrides and amino-TEMPO (T) building-blocks on a solid support. ${ }^{6}$ The coded sequences of these polymers are based on a binary-monomer code introduced in previous publications. $^{6,7}$ Typically, 0 and 1 bits are encoded by two amide synthons with mass of 71.0 and 85.1 Da, respectively. Although the mass difference between these two motifs is small, this molecular digital code can be read by MS/MS. ${ }^{7}$ In the present work, the poly(alkoxyamine amide)s were prepared following the strategy shown in Fig. 1. A library of four $\alpha$-acid, $\omega$-bromo oligo(alkoxyamine amide)s containing all possible information dyads, i.e. 0T0, 0T1, 1T0 and 1T1, was synthesized (Fig. 1a). These oligomers were then used as building-blocks to construct longer polymers. As shown in Fig. 1b, the synthesis was performed on a solid support containing a premade amino-terminated sequence, which can be reacted with any dyad of the library via carboxylic acid/amine coupling (step (i) in Fig. 1b).

Step (i) is orthogonal and does not require any protecting group. The resulting bromo-terminated sequences can be afterwards activated by $\mathrm{CuBr}$ and reacted with $\mathrm{T}$ by orthogonal radical-radical coupling (step (ii) in Fig. 1b). ${ }^{11}$ The sequential 
a.
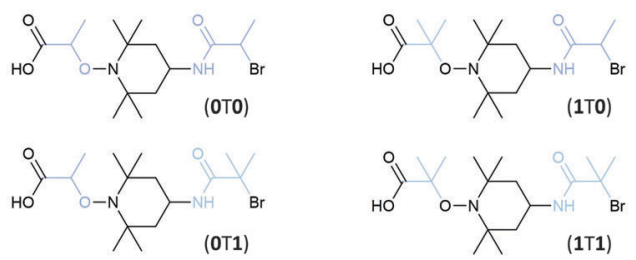

b.

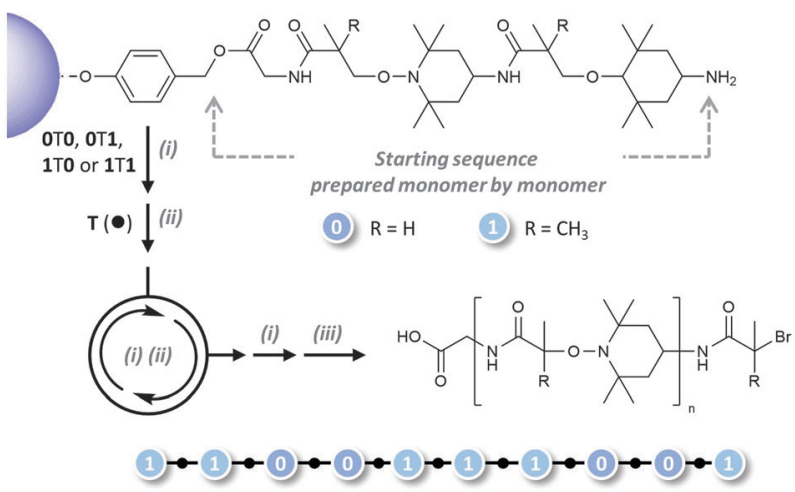

Fig. 1 General strategy studied in the present work for the synthesis of sequence-encoded poly(alkoxyamine amide)s. (a) Molecular structure of the dyad-encoded oligomers used as building-blocks in the iterative synthesis. (b) Synthesis of long macromolecules by stepwise oligomer coupling. Experimental conditions: (i) carboxylic acid-amine coupling: THF, HBTU, DIPEA, (ii) radical-radical coupling: TEMPO- $\mathrm{NH}_{2}(\mathrm{~T}), \mathrm{CuBr}, \mathrm{Me}_{6} \mathrm{TREN}$, DMSO, (iii) cleavage: TFA, $\mathrm{CH}_{2} \mathrm{Cl}_{2}$.

use of steps (i) and (ii) allows rapid construction of sequencecoded poly(alkoxyamine amide)s. In principle, any desired digital sequence can be constructed using this simple strategy.

The sequence-coded dyads were prepared by conventional iterative synthesis on an unmodified Wang resin $\mathbf{R}_{\mathbf{W}}$ as shown in Fig. 2. These sequences were prepared using $\mathrm{T}$ and two coded anhydrides a-0 and $\mathbf{a - 1} .^{6}$ In all cases, the first anhydride was reacted with the free $\mathrm{OH}$ group of the Wang motif to afford a cleavable ester bond. Afterwards, the desired sequence was synthesized using three additional steps. The four oligomers were characterized by ${ }^{1} \mathrm{H}$ and ${ }^{13} \mathrm{C}$ NMR as well as electrospray high resolution mass spectrometry (ESI-HR-MS). All these methods
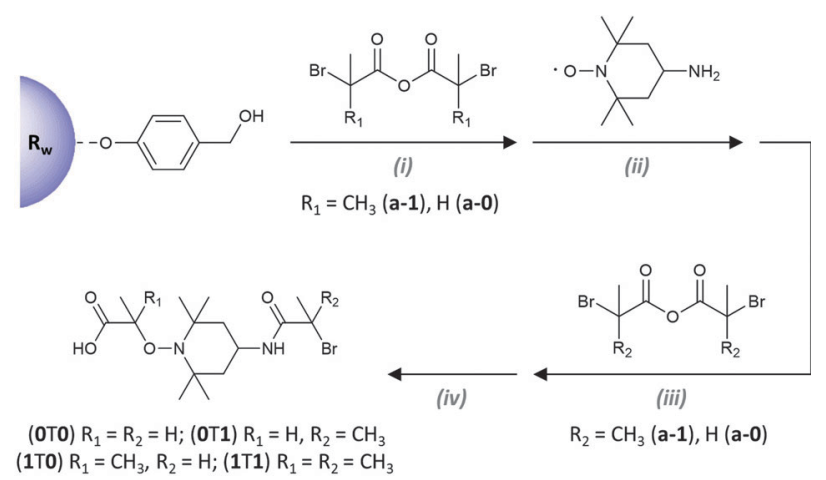

Fig. 2 Synthesis of the dyad-encoded oligomers. Experimental conditions: (i) anhydride-alcohol reaction: HBTU, DMAP, THF, microwave irradiation, (ii) radical-radical coupling: $\mathrm{CuBr}, \mathrm{Me}_{6} \mathrm{TREN}, \mathrm{DMSO}, \mathrm{RT}$, (iii) anhydride-amine coupling: base, THF, RT, (iv) cleavage: TFA, $\mathrm{CH}_{2} \mathrm{Cl}_{2}$. confirmed the synthesis of monodisperse species. As pointed out in earlier publications, ${ }^{6,7}$ it is important to note that the use of carbon-centered tertiary radicals in step (ii) leads only to marginal H-transfer. This is explained by the fact that this side-reaction is generally disfavored when mild reaction temperatures are used. ${ }^{11 a, 12}$

The dyad library was afterwards evaluated for the synthesis of long poly(alkoxyamine amide)s. As mentioned above, a solidsupport containing a short amino-functional sequence, i.e., $\mathbf{R}_{\mathbf{W}} \mathbf{G 1 T 1 T}$, was used to start the syntheses. This modified support was obtained by 4-steps iterative synthesis on a glycine-loaded Wang resin $\mathbf{R}_{\mathbf{w}} \mathbf{G}$. Although not strictly mandatory, ${ }^{7}$ glycine is used as a convenient $\alpha$-chain-end that leads to easily traceable fragments in MS/MS sequencing. The integrity of the starting sequence G1T1T was verified by cleaving a small fraction from the support. However, prior to cleavage and characterization, a fifth unit was attached to the sequence since Br-terminated oligomers are easier to characterize than $\mathrm{NH}_{2}$-functional ones.

In order to evaluate the reliability of the approach, a homopolymer was first synthesized by successive ligation of the dyad 1 T1 on $R_{\mathbf{W}}$ G1T1T. In particular a polymer containing 19 monomer units (i.e. 10 coded amide units and $9 \mathrm{~T}$ spacers) was prepared. As shown in Fig. 1, it was obtained by repeating 3 times the cycle involving successive steps (i) and (ii) followed by a final step (i) and cleavage (iii) from the resin. After each step (i), a small fraction of the formed polymer was cleaved from the resin and analyzed by mass spectrometry (Fig. S1-S4, ESI $\dagger$ ). In all cases, the expected species were observed. In particular, characterization of the exact mass by ESI-HR-MS confirmed the formation of the targeted polymers (Fig. 3a). However, slight signs of polydispersity can be observed in the ESI-MS spectrum of $\alpha-[1-T]_{7}-1-\omega$ and more pronounced defects can be seen in the final spectrum of $\alpha-[1-T]_{9}-1-\omega$. This was also confirmed by size exclusion chromatography (SEC) measurements, which indicated an apparent $D$ value of 1.03 for $\alpha-[1-T]_{9}-1-\omega$ (Fig. S5, ESI $\dagger$ ). As discussed in a previous publication, ${ }^{6}$ SEC chromatograms of uniform species should be interpreted with caution since apparent polydispersity may result from classical peak broadening. ${ }^{13}$ However, the bimodality seen in Fig. S5 (ESI $\dagger$ ) is probably not an artefact and suggests that the last dyad coupling step was not fully quantitative in the studied conditions. Nevertheless, after each step (i), the intermediate sequence was characterized by MS/MS sequencing (Fig. S6-S8, ESI $\dagger$ ). The polymers underwent fragmentation pathways described in earlier publications ${ }^{6,7}$ and the expected sequences were confirmed. As an example, Fig. $3 \mathrm{~b}$ and $\mathrm{c}$ show the MS/MS sequencing of the final polymer $\alpha-[1-T]_{9}-1-\omega$. These results indicate that sequence-defined poly(alkoxyamine amide)s can be efficiently constructed by successive dyad-ligation.

The concept was then extended to the synthesis of sequencecoded polymers. A series of polymers containing different coded sequences was synthesized and characterized (Table 1). All these samples were prepared using the strategy of Fig. 1. For example, entry 1 in Table 1 was constructed on $\mathbf{R}_{\mathbf{W}} \mathbf{G 1 T 1 T}$ by successive ligation two 0T1 dyads while entry 2 involved 0T1 prior to 1T0. Fig. S9 and S10 (ESI $\dagger$ ) show the ESI-MS characterization of the obtained digitally-encoded polymers. In all cases, 
a.

\begin{tabular}{lll}
\hline Sequence & $m / z_{\text {th }}$ & $m / z_{\text {exp }}$ \\
\hline$\alpha-[1 T]_{3} 1-\omega$ & $472.7751[\mathrm{M}+2 \mathrm{H}]^{2+}$ & 472.7744 \\
$\alpha-[\mathbf{1 T}]_{5} \mathbf{1}-\omega$ & $712.9589[\mathrm{M}+2 \mathrm{H}]^{2+}$ & 712.9586 \\
$\alpha-[1 \mathrm{1T}]_{7} \mathbf{1 - \omega}$ & $953.1427[\mathrm{M}+2 \mathrm{H}]^{2+}$ & 953.1432 \\
$\alpha-[\mathbf{1 T}]_{9} \mathbf{1 - \omega}$ & $1193.3265[\mathrm{M}+2 \mathrm{H}]^{2+}$ & 1193.3264 \\
\hline
\end{tabular}

b.

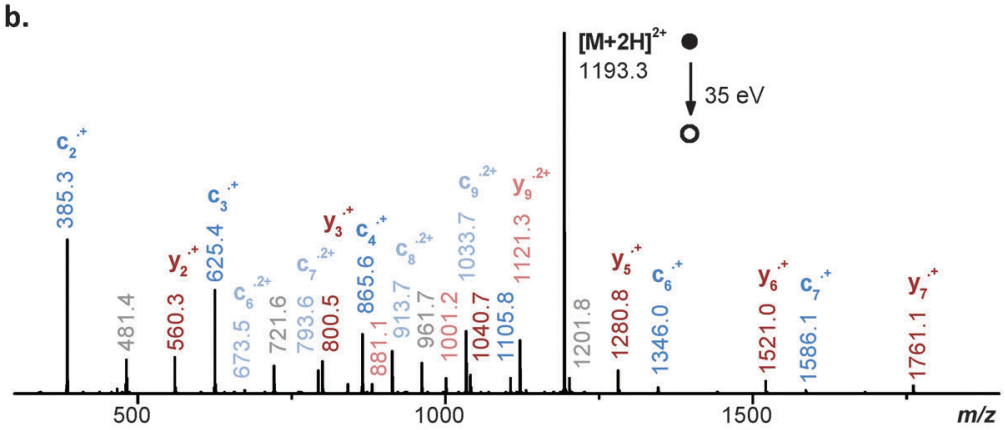

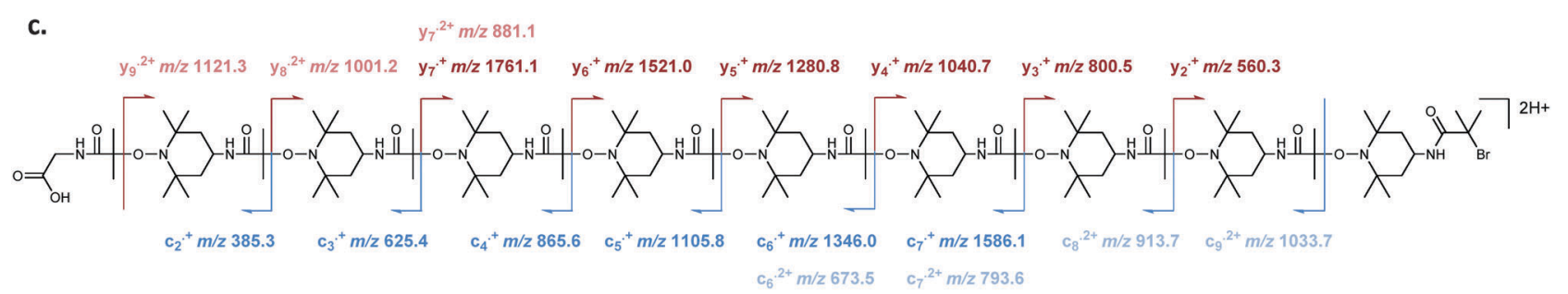

Fig. 3 Characterization of a homopolymer obtained by successive oligomer ligation of the dyad 11 on a solid support. (a) Experimental molar mass measured by ESI-HR-MS at different stages of the stepwise construction. (b) ESI-MS/MS spectrum obtained after collisional activation (35 eV) of the $\mathrm{m} / \mathrm{z} 1193.3$ precursor ion $\left[\alpha-[\mathbf{1}-\mathrm{T}]_{9}-\mathbf{1}-\omega+2 \mathrm{H}\right]^{2+}$. The $\mathrm{m} / \mathrm{z}$ values in grey correspond to protonated cyclic $(\mathbf{1 T})_{n}$ internal fragments. (c) Interpretation of the MS/MS fragmentation of the poly(alkoxyamine amide) $\alpha-[1-T]_{9}-1-\omega$.

Table 1 Experimental molar mass measured by ESI-HR-MS for doubly protonated molecules of different sequence-coded polymers prepared by successive dyad-ligation

\begin{tabular}{lll}
\hline Sequence $^{a}$ & $m / z_{\text {th }}$ & $m / z_{\text {exp }}$ \\
\hline$\alpha-(1-T-1-T)-(0-T-1)-T-(0-T-1)-\omega$ & $698.9433[\mathrm{M}+2 \mathrm{H}]^{2+}$ & 698.9416 \\
$\alpha-(1-T-1-T)-(0-T-1)-T-(1-T-0)-\omega$ & $698.9433[\mathrm{M}+2 \mathrm{H}]^{2+}$ & 698.9435 \\
$\alpha-(1-T-1-T)-(1-T-1)-T-(1-T-0)-\omega$ & $705.9511[\mathrm{M}+2 \mathrm{H}]^{2+}$ & 705.9511
\end{tabular}

${ }^{a}$ The parenthesis in the sequence are only displayed for clarity and indicate the synthons that were used to build the polymers.

monodisperse or near monodisperse samples were observed. Moreover, the measured exact mass matched closely theoretical value for all samples (Table 1). These results imply that the dyad-ligation strategy is not only efficient for homopolymers but also for copolymers. Perhaps more importantly, it was verified in all cases that the expected sequences were formed thanks to their unique MS/MS dissociation pattern (Fig. 4 and Fig. S11 and S12, ESI $\dagger$ ). Even species exhibiting very slight differences in their sequence, such as location of the second $\mathbf{0}$ coding units in entries 1 and 2, were discriminated (Fig. 4). The peculiar fragmentation behavior of poly(alkoxyamine amide)s was shown to consist of competitive homolytic cleavages of any $\mathrm{C}-\mathrm{ON}$ bond between a coding unit and TEMPO moiety, leading to two product ion series holding either one or the other chain terminations. $^{7}$ As a result, the mass difference between two consecutive fragments within a given series can only be equal to $226.2 \mathrm{Da}$ (T-0) or $240.2 \mathrm{Da}$ (T-1). Consequently, any unknown coded sequence can be read in a straightforward manner from its MS/MS spectrum by simply measuring the $\mathrm{m} / \mathrm{z}$ distance between peaks within a given series. For example, in Fig. 4a, the first fragment at $m / z 385.3$ assigned to $\left[\alpha-1-\mathrm{T}-\mathbf{1}^{\bullet}+\mathrm{H}\right]^{+}$ (named $\mathrm{c}_{2}{ }^{\bullet+}$ ) and upper homologues constituting this series,
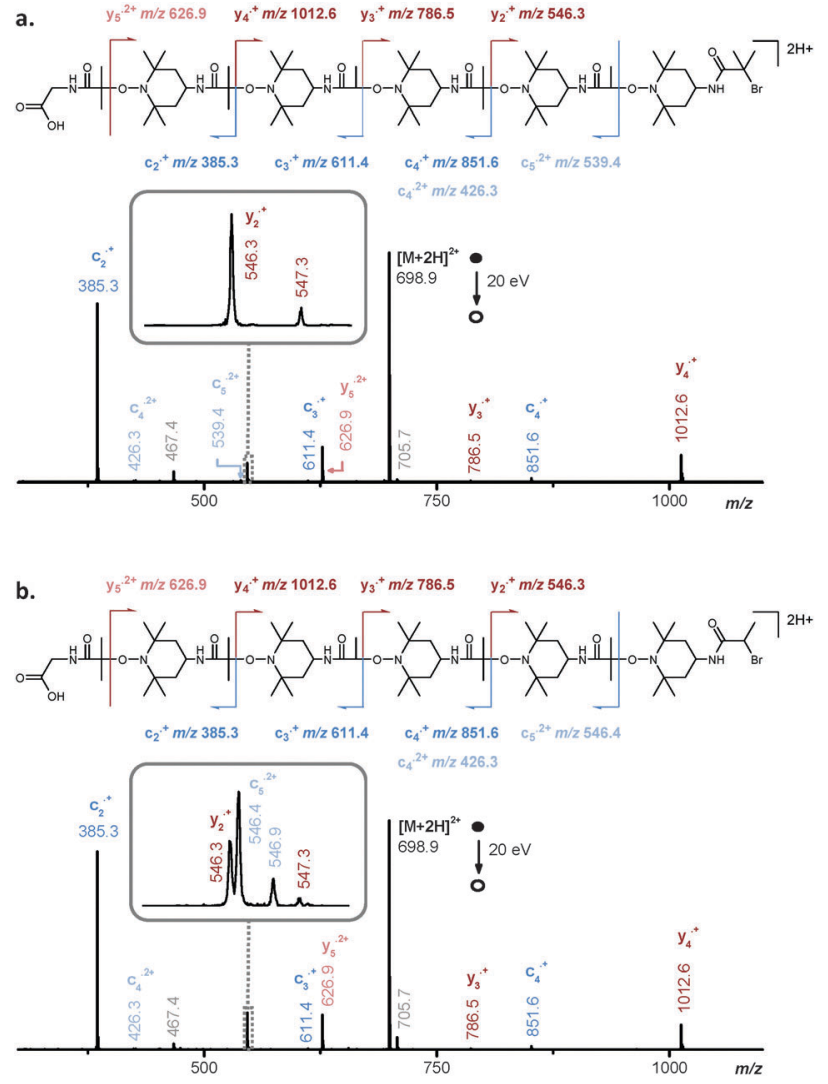

Fig. 4 MS/MS sequencing of isomeric sequence-coded copolymers (a) $\alpha$-(1-T-1-T)-(0-T-1)-T-(0-T-1)- $\omega$; (b) $\alpha$-(1-T-1-T)-(0-T-1)-T-(1-T-0)- $\omega$. Both ESI-MS/MS spectra were obtained after collisional activation (20 eV) of doubly charged precursor ions at $\mathrm{m} / \mathrm{z}$ 698.9. The $\mathrm{m} / \mathrm{z}$ values in grey correspond to internal or secondary fragments. 
$\mathrm{c}_{3}{ }^{\bullet+}$ at $m / z 611.4(\Delta m / z 226.2:+\mathrm{T}-0), \mathrm{c}_{4}{ }^{\bullet+}$ at $m / z 851.6(\Delta m / z$ 240.2: $+\mathrm{T}-1)$ also detected as $\mathrm{c}_{4}{ }^{\cdot 2+}$ at $m / z 426.3$, and $\mathrm{c}_{5}{ }^{\cdot 2+}$ at $\mathrm{m} / z 539.4$ $(\Delta m / z 113.1=226.2 / 2:+\mathrm{T}-0)$, allowed the chain to be reconstructed from the left- to the right-hand side as $\alpha-\mathbf{1}-\mathrm{T}-\mathbf{1}-\mathrm{T}-\mathbf{0}-\mathrm{T}-\mathbf{1}-\mathrm{T}-\mathbf{0}$. Complementarily, the $\mathrm{y}_{\mathrm{i}}{ }^{\bullet \mathrm{z}^{+}}$series composed of $\mathrm{m} / \mathrm{z} 546.3$ $\left[{ }^{\bullet} \mathrm{T}-\mathbf{0}-\mathrm{T}-1-\mathrm{Br}+\mathrm{H}\right]^{+}, \mathrm{m} / \mathrm{z} 786.5(\Delta m / z \quad 240.2:+1-\mathrm{T}), \mathrm{m} / \mathrm{z} 1012.6$ $(\Delta m / z$ 226.2: $+\mathbf{0}-\mathrm{T})$, and the doubly charged $m / z 626.9$ fragment $(\Delta m / z 240.2 / 2:+1-T)$ was consistent with a T-1-T-0-T-1-T-0-T-1-Br structure. Combining these two partial sequences unequivocally conducted to the unique $\alpha-1-\mathrm{T}-1-\mathrm{T}-\mathbf{0}-\mathrm{T}-1-\mathrm{T}-\mathbf{0}-\mathrm{T}-1-\mathrm{Br}$ structural conclusion.

Due to issues regarding location of the adducted protons, ${ }^{7}$ all but the first and the last $\mathrm{C}-\mathrm{ON}$ bond cleavages produced a pair of complementary fragments. Since sequences in entries 1 and 2 only differed by the two last units, they gave rise to the same series of fragments holding the $\omega$ end-group (that is, $\mathrm{y}_{\mathrm{i}}{ }^{\bullet+}$ ) as shown in Fig. 4. In contrast, they were distinguished based on their $\mathrm{c}_{5}{ }^{\cdot 2+}$ product ion, respectively detected at $\mathrm{m} / \mathrm{z} 539.4$ and $m / z 546.4$. The peak of the latter $\mathrm{c}_{5}{ }^{\bullet 2+}$ fragment at $m / z 546.4$ could be separated from the signal of the $m / z 546.3 \mathrm{y}_{2}{ }^{\circ+}$ thanks to the high resolution capability of the oaTOF mass analyzer. As shown in the insets of Fig. 4, this assignment was supported by ${ }^{13} \mathrm{C}$ isotopic peaks observed at $\mathrm{m} / \mathrm{z} 547.3$ for the singly charged $\mathrm{y}_{2}{ }^{\bullet+}$ and $m / z 546.9$ for the doubly charged $\mathrm{c}_{5}{ }^{\bullet+}$, as well as by the $\mathrm{m} / \mathrm{z}$ shift experienced by the $\mathrm{y}_{\mathrm{i}}{ }^{\bullet \mathrm{z}+}$ fragments only in the MS/MS spectrum of the ${ }^{81} \mathrm{Br}$-containing precursor (Fig. S11, ESI $\dagger$ ). The MS/MS fragmentation observed for entry 3 also confirmed the targeted sequence (Fig. S12, ESI $\dagger$ ).

In summary, digitally-encoded poly(alkoxyamine amide)s were synthesized by successive macromolecular ligation of dyads. Using a simple library of four reactive dyads, any desired binary sequence can be obtained. As a proof of concept, homopolymers and copolymers were prepared in this work. MS/MS sequencing measurements confirmed that the expected sequences were formed in all cases. On the whole, this strategy is fast and efficient and therefore greatly simplifies the solid-phase synthesis of information-containing macromolecules. It should be however remarked that slight polydispersity was observed after performing several iterations on the resin. This implies that capping steps and HPLC purification are probably mandatory if long polymer chains are targeted. Nevertheless, the present work opens up interesting avenues for the design of sequence-coded materials. ${ }^{2 b}$

\section{Notes and references}

1 J.-F. Lutz, M. Ouchi, D. R. Liu and M. Sawamoto, Science, 2013, 341, 1238149.

2 (a) H. M. Colquhoun and J.-F. Lutz, Nat. Chem., 2014, 6, 455-456; (b) J.-F. Lutz, Macromolecules, 2015, 48, 4759-4767.

3 H. Mutlu and J.-F. Lutz, Angew. Chem., Int. Ed., 2014, 53, 13010-13019.

4 A. Al Ouahabi, L. Charles and J.-F. Lutz, J. Am. Chem. Soc., 2015, 137, 5629-5635.

5 (a) S. Pfeifer, Z. Zarafshani, N. Badi and J.-F. Lutz, J. Am. Chem. Soc., 2009, 131, 9195-9196; (b) T. T. Trinh, L. Oswald, D. Chan-Seng and J.-F. Lutz, Macromol. Rapid Commun., 2014, 35, 141-145; (c) T. T. Trinh, L. Oswald, D. Chan-Seng, L. Charles and J.-F. Lutz, Chem. - Eur. J., 2015, 21, 11961-11965.

6 R. K. Roy, A. Meszynska, C. Laure, L. Charles, C. Verchin and J.-F. Lutz, Nat. Commun., 2015, 6, 7237.

7 L. Charles, C. Laure, J.-F. Lutz and R. K. Roy, Macromolecules, 2015, 48, 4319-4328.

8 (a) T. T. Trinh, C. Laure and J.-F. Lutz, Macromol. Chem. Phys., 2015, 216, 1498-1506; (b) P. Espeel, L. L. G. Carrette, K. Bury, S. Capenberghs, J. C. Martins, F. E. Du Prez and A. Madder, Angew. Chem., Int. Ed., 2013, 52, 13261-13264; (c) J. Vandenbergh, G. Reekmans, P. Adriaensens and T. Junkers, Chem. Commun., 2013, 49, 10358-10360; (d) M. Porel and C. A. Alabi, J. Am. Chem. Soc., 2014, 136, 13162-13165; (e) S. C. Solleder, K. S. Wetzel and M. A. R. Meier, Polym. Chem., 2015, 6, 3201-3204.

9 (a) S. S. Reddy, X. Dong, R. Murgasova, A. I. Gusev and D. M. Hercules, Macromolecules, 1999, 32, 1367-1374; (b) G. M. Brooke, J. A. Hugh MacBride, S. Mohammed and M. C. Whiting, Polymer, 2000, 41, 6457-6471; (c) K. Takizawa, C. Tang and C. J. Hawker, J. Am. Chem. Soc., 2008, 130, 1718-1726; (d) S. Binauld, C. J. Hawker, E. Fleury and E. Drockenmuller, Angew. Chem., Int. Ed., 2009, 48, 6654-6658.

10 S. B. H. Kent, Chem. Soc. Rev., 2009, 38, 338-351.

11 (a) K. Matyjaszewski, B. E. Woodworth, X. Zhang, S. G. Gaynor and Z. Metzner, Macromolecules, 1998, 31, 5955-5957; (b) J. Kulis, C. A. Bell, A. S. Micallef, Z. Jia and M. J. Monteiro, Macromolecules, 2009, 42, 8218-8227; (c) A. Debuigne, M. Hurtgen, C. Detrembleur, C. Jérôme, C. Barner-Kowollik and T. Junkers, Prog. Polym. Sci., 2012, 37, 1004-1030.

12 (a) W. Lin, B. Huang, Q. Fu, G. Wang and J. Huang, J. Polym. Sci., Part A: Polym. Chem., 2010, 48, 2991-2999; (b) U. S. Gunay, H. Durmaz, E. Gungor, A. Dag, G. Hizal and U. Tunca, J. Polym. Sci., Part A: Polym. Chem., 2012, 50, 729-735.

13 L. Marais, Z. Gallot and H. Benoît, J. Appl. Polym. Sci., 1977, 21, 1955-1964. 